\title{
Secretion of glucagon-like peptide-2 responds to nutrient intake but not glucose provision in milk-fed calves
}

\author{
J. J. Castro, ${ }^{*}$ S. Y. Morrison, † A. Hosseinni,† J. J. Loor,† J. K. Drackley,† and I. R. Ipharraguerre ${ }^{1}$ \\ *Department of Dairy Science, Virginia Tech, Blacksburg 24060 \\ †Department of Animal Sciences, University of Illinois, Urbana 24060 \\ fInstitute of Human Nutrition and Food Science, University of Kiel, Kiel, Germany D-24118
}

\section{ABSTRACT}

Glucagon-like peptide 2 (GLP-2) is a peptide released by the lower gut that has potent trophic and restorative effects on the intestinal epithelium. Two experiments were conducted to assess the effects of feeding rate and either metabolizable or nonmetabolizable glucose supplementation on GLP-2 concentrations in plasma and intestinal development in Holstein calves. In the first experiment, 48 newborn calves were assigned to 12 treatments $(\mathrm{n}=4)$ corresponding to the factorial combination of 4 milk feeding amounts $[1.75,1.32$, 0.88 , and $0.44 \%$ of body weight (BW) as dry matter $(\mathrm{DM})]$ and 3 oral supplementation treatments (nonsupplemented, glucose-supplemented, and 3-O-methyl glucose-supplemented). In the second experiment 30 newborn calves $(\mathrm{n}=10)$ were fed milk at a fixed rate of $1.75 \%$ of $\mathrm{BW}$ as DM and assigned to the same glucose supplementation treatments used in experiment 1 to investigate effects on intestinal development. In the first experiment, we found a saturating response of plasma GLP-2 to increasing feeding levels. The feeding rate at which $50 \%$ of the maximal GLP-2 release occurred was estimated to be $0.53 \%$ of $\mathrm{BW}$ as DM or $30.3 \%$ of the maximum feeding rate $(1.75 \%$ of $\mathrm{BW}$ as $\mathrm{DM})$, whereas maximal secretion was estimated to be about 98.6 $\mathrm{pmol} / \mathrm{L}$. In turn, feeding 75,50 , or $25 \%$ of the maximal feeding rate (i.e., $1.75 \% \mathrm{BW}$ as DM) resulted in plasma GLP-2 concentrations 87,72 , and $49 \%$ of that in fully fed calves, respectively. Neither metabolizable nor nonmetabolizable glucose supplementation affected GLP-2 secretion and no interaction with feed intake level was detected. In the second experiment, no effect of glucose supplementation was observed on intestinal growth, mucosal cell proliferation, or expression of genes related to the actions of GLP-2. Nonetheless, we observed that

Received October 13, 2015.

Accepted February 20, 2016.

${ }^{1}$ Corresponding author: ipharraguerre@foodsci.uni-kiel.de a pool of genes of the GLP-2 signaling pathway was more abundantly and coordinately regulated in the colon than in the ileum of these animals, indicating an opportunity for dietary induction of the peptide in this organ. In conclusion, during this experiment, plasma GLP-2 concentrations responded in a diminishing return fashion to milk intake but not to glucose supplementation, even at milk consumption levels of only $0.4 \%$ of BW as DM.

Key words: glucagon-like peptide 2 (GLP-2), intestine, milk feeding

\section{INTRODUCTION}

Glucagon-like peptide 2 (GLP-2) is an intestinally secreted peptide with trophic and regenerative properties for the intestinal epithelium (Burrin et al., 2000). Genes involved in the GLP-2 pathway are expressed along the gastrointestinal tract of ruminants (Connor et al., 2010), and the GLP-2 receptor appears to be fully operative as greater epithelial development and blood flow have been recorded in response to therapeutic application of exogenous GLP-2 in ruminants (TaylorEdwards et al., 2011; Connor et al., 2013). This peptide is known to induce proliferation of crypt cells, reduce mucosal apoptosis, decrease intestinal barrier permeability, and dampen inflammation in the gut (Drucker et al., 1996; Burrin et al., 2003; Drucker, 2005). These properties make it a potential target to maintain or enhance intestinal integrity in newborn milk-fed calves.

Secretion of GLP-2 is largely driven by luminal delivery of nutrients (Burrin et al., 2000), and its secretion has been augmented in response to greater energy intake in steers (Taylor-Edwards et al., 2010). In addition to whole-feed intake, specific nutrients such as glucose might stimulate GLP-2 (Brubaker and Anini, 2003; Shirazi-Beechey et al., 2011). Infusing the duodenum of weaned sheep with glucose for $4 \mathrm{~d}$ increased its rate of transport 40- to 80-fold above that in control animals (Shirazi-Beechey et al., 1991), which may have been caused by an increase in GLP-2 secretion elicited 
through activation of the sweet taste receptor located in the gut (Shirazi-Beechey et al., 2011).

Whereas a positive effect of increased energy intake and glucose infusion on GLP-2 secretion and intestinal function has been observed in ruminants (ShiraziBeechey et al., 1991; Taylor-Edwards et al., 2010), no information is available on such responses in newborn milk-fed calves. However, knowledge regarding the effect of milk intake on endogenous GLP-2 secretion could be useful to identify when calves under usual farming circumstances (e.g., diarrhea episodes, restricted milk feeding) can benefit from exogenous GLP-2 administration or application of certain feed additive strategies with therapeutic potential that could be easier to implement under commercial schemes of animal production (Connor et al., 2015; de Diego-Cabero et al., 2015). Understanding the GLP-2 response to the enteral supply of nutrients in milk-fed calves, however, precludes the determination of the milk intake range in which GLP-2 secretion could be stimulated by nonpharmacological means (i.e., dietary interventions). Furthermore, addressing whether glucose supplementation can affect circulating GLP-2 concentrations when calves are fed variable amounts of milk will be useful to assess its potential to support intestinal integrity. Finally, given the absence of data in calves, this information will also be relevant to consider effect sizes, inter-calf variability, and adequate sample sizes in future research on GLP-2 with newborn calves where variation in food intake is to be considered.

The specific set of hypotheses tested in this work were that (1) feeding rate affects GLP-2 secretion in young calves; (2) the effect of metabolizable and nonmetabolizable glucose (i.e., 3-O-methyl glucose, 3-O-M-G) on GLP-2 secretion depends on the feed intake level; and (3) supplementation with glucose or a nonmetabolizable glucose analog can effect organ size, epithelial morphometric dimensions, and proliferation compared with nonsupplemented calves and that this effect may differ between the small and large intestine. The aim of this work was to characterize the response of GLP-2 secretion to a range of feed intake amounts resembling the anorexic variation between intestinally healthy and diarrhea-ill calves, and to test the effect of metabolizable and nonmetabolizable glucose supplementation on GLP-2 secretion and intestinal development measures.

\section{MATERIALS AND METHODS}

Two experiments were conducted. In the first, we assessed the effect of feeding rate, glucose or 3-O-M$\mathrm{G}$ supplementation, and their interaction on plasma GLP-2 concentrations. In the second experiment, we investigated the effect of glucose or $3-\mathrm{O}-\mathrm{M}-\mathrm{G}$ supple- mentation on epithelial cell proliferation, histological measures, and mRNA expression of genes related to the GLP-2 signaling pathway and intestinal development and function.

\section{Experiment 1}

All procedures were conducted with approval of the University of Illinois Institutional Animal Care and Use Committee (Urbana, IL). Forty-eight newborn male Holstein calves, 4 to $5 \mathrm{~d}$ old, were purchased and transported to the University of Illinois Nutrition Field Laboratory research site. Calves were selected at a local farm in east-central Illinois. At time of selection, blood samples were taken from the jugular vein into a $10-\mathrm{mL}$ evacuated serum separation tube (Becton Dickinson, Rutherford, NJ). Blood was centrifuged at 1,300 $\times g$ for $15 \mathrm{~min}$, and a refractometer was used to determine total protein in the serum for all potential calves. Calves were selected based on total protein and visual health assessment and were identified with ear tags. All calves selected were given $2 \mathrm{mg}$ of Se plus $100 \mathrm{mg}$ of vitamin E (BO-SE, Merck Animal Health, Kenilworth, NJ), 1 $\mathrm{mL}$ of vitamins $\mathrm{A}$ and $\mathrm{D}$ (Sparhawk Laboratories Inc., Lenexa, KS), and $2 \mathrm{~mL}$ of a nasal vaccine against bovine respiratory syncytial virus (Inforce 3, Pfizer, New York, NY). If a calf was chosen for the trial and had a total protein of $<5.5 \mathrm{~g} / \mathrm{dL}$, the calf was given $50 \mathrm{~mL}$ of antiserum (Bovisera, Colorado Serum Co., Denver, $\mathrm{CO}$ ) and $20 \mathrm{~mL}$ of clostridial $\mathrm{C}$ and $\mathrm{D}$ antitoxin (Boehringer Ingelheim, Ridgefield, CT). Calves were housed in individual calf hutches with straw bedding to contain pathogen shedding and provide comfort, respectively. Upon arrival, calves were weighed. Complete blocks of calves were made based upon BW at arrival and, within each block, the 12 treatments were randomly assigned $(\mathrm{n}=4)$. In both experiments, calves were fed a commercial milk replacer (Excelerate, Milk Specialties Global, Eden Prairie, MN), which contained, on average, $28.4 \% \mathrm{CP}, 44 \%$ lactose, and $15.8 \%$ fat on a DM basis.

Treatment Allotment. Experiment 1 included 12 treatments from a factorial combination of 2 factors: feeding rate and supplement treatment. Feeding rate comprised 4 levels: 25, 50, 75, and $100 \%$ of a standard feeding level of $1.75 \%$ of BW as DM on experimental d 6 and 7. In turn, supplement treatments were (1) control (commercial milk replacer without supplementation), (2) commercial milk replacer plus glucose (220 $\mathrm{mg} / \mathrm{kg}$ of BW daily), and (3) commercial milk replacer plus 3-O-M-G (6 mg/kg of BW daily).

Dose of glucose was based on a published study (Shirazi-Beechey et al., 1991) where activity of the sodium-glucose co-transporter 1 (SGLT1) in adult sheep 
(not fed milk) infused with $1.5 \mathrm{~L} / \mathrm{d}$ of $30 \mathrm{~m} M$ D-glucose solutions achieved a $40-$ to 80 -fold increase in the rate of glucose transport. One and a half liters of a $30 \mathrm{mM}$ glucose solution provides about $8.1 \mathrm{~g}$ of glucose per day. Based on this research, we dosed $\sim 10 \mathrm{~g} /$ calf daily. However, we must also account for the intake of hexose (i.e., $1 \mathrm{~mol}$ of glucose $+1 \mathrm{~mol}$ of galactose) from lactose in milk. For a 40-kg calf, with milk replacer DMI ranging from 0.44 or $1.75 \%$ of $\mathrm{BW}$, glucose-equivalent hexose intake is estimated to range from 77 to 310 $\mathrm{g} / \mathrm{d}$. Therefore, glucose-equivalent intake in the present study was approximately 9 to 38 times higher than that achieved in mature sheep by Shirazi-Beechey et al. (1991). Although inferring glucose doses from mature ruminants to elicit signaling in preruminant newborns might be inadequate given the different developmental stages, the lack of information on this subject with newborn calves forced us to use available information from sheep.

The 3-O-M-G has been used previously at doses of approximately $0.16 \mathrm{~g}$ per $\mathrm{kg}$ of $\mathrm{BW} / \mathrm{d}$ in sheep to upregulate SGLT1 activity (Shirazi-Beechey et al., 1991), and at $\sim 1.1 \mathrm{~g}$ per $\mathrm{kg}$ of $\mathrm{BW} / \mathrm{d}$ in mice to increase glucose-dependent insulinotropic peptide (GIP) and GLP-1 secretion (Moriya et al., 2009). We set a dose of $6 \mathrm{mg} / \mathrm{kg}$ of BW daily to supply $\sim 300 \mathrm{mg} / \mathrm{d}$ for a $50-\mathrm{kg}$ calf.

The adaptation and treatment periods were as follows. From d 1 to 5, calves were adapted to the milk replacer diet and housing conditions. Milk replacers were reconstituted to $12.5 \%$ solids and fed in 2 meals per day. Calves were fed milk replacer at a daily rate of $1.25 \%$ of BW (DM basis) for the first $2 \mathrm{~d}$. During d 3 to 5 , the amount of milk replacer was increased to $1.5 \%$ of BW. On d 6 and 7, calves were fed according to the experimental feeding rates described above $(25$, 50,75 , or $100 \%$ of the standard rate of $1.75 \%$ of BW as DM). On d 8, experimental measurements took place. Supplemental glucose treatments were introduced on d 6. Briefly, blood samples $(10 \mathrm{~mL})$ were taken from the jugular vein at $-15,15,30,60,90$, and $240 \mathrm{~min}$ relative to feeding time for measurement of GLP-2 concentrations in plasma. Supplemental glucose was mixed with the milk replacer. After $240 \mathrm{~min}$, the experimental procedure ended and standard feeding resumed at a rate of $1.75 \%$ of $\mathrm{BW}$ as DM for all calves.

Before sample collection on d 8, calves were brought inside and tied in stalls. Calves were clipped on the neck around the jugular area to ease location of the vein for needle insertion. Blood samples were collected by jugular venipuncture using 18-gauge hypodermic disposable needles (3.8 cm long). Blood samples were collected into 10-mL tubes containing EDTA (Becton Dickinson) plus a pyrrolic acid-based dipeptidyl peptidase 4 inhibitor (catalog \# DPP4, Millipore, St. Charles, MO). Samples were kept on ice for 15 min after collection and then centrifuged at room temperature for $15 \mathrm{~min}$ at $2,500 \times g$. The plasma was extracted and frozen at $-20^{\circ} \mathrm{C}$ until further analyses. All plasma samples $(700 \mu \mathrm{L})$ were extracted in a final concentration of $75 \%$ ethanol before GLP-2 measurements, as previously described (Taylor-Edwards et al., 2011). Intact GLP-2 was measured using a radioimmunoassay previously described (Hartmann et al., 2000). Briefly, the antiserum (code no. 92160, developed as described in Wøjdemann et al., 1998) is directed against the $\mathrm{N}$ terminus of GLP2 and therefore measures only fully processed GLP-2 of intestinal origin. For standards, we used recombinant human GLP-2 and the tracer was ${ }^{125}$ I-labeled rat GLP2 with an Asp33 $\rightarrow$ Tyr33 substitution. The sensitivity was $2 \mathrm{pmol} / \mathrm{L}$ and intraassay coefficient of variation was $<6 \%$.

Statistical Analysis. To test the hypothesis that plasma GLP-2 plasma concentration is affected by milk replacer feeding rate, glucose supplementation, or their interaction, secretion response data were analyzed as follows. Plasma GLP-2 concentrations visually appeared to follow a saturating pattern in response to feeding rate (Figure 1, left panel), albeit with seemingly large variation among calves within each feeding rate group. Therefore, we evaluated 4 possible contrasting models: a constant model: [GLP-2] = constant, where average plasma GLP-2 does not vary with feeding rate; a linear model: [GLP-2] $=a+b \times x$, where average plasma GLP-2 increases linearly with feeding rate; an exponential asymptotic model: $[$ GLP-2 $]=a \times\left(1-e^{-b \times \text { Feeding Rate }}\right)$, and a Michaelis-Menten model: $[\mathrm{GLP}-2]=a / 1+\frac{b}{x}$, where average plasma GLP-2 increases in a saturating manner. In all cases, errors were assumed to follow a normal distribution with constant variance $\left[\operatorname{NIID}\left(0, \sigma^{2}\right)\right]$. The 4 models were compared based on Akaike information criteria (AIC) and Bayesian information criteria (BIC), which indicate the likelihood of observing the data given a particular model and include a penalty for an increasing number of parameters. Lower values of AIC and BIC indicate a better model. The residual standard error (RSE) was used to compare models with lower deviation between predicted and observed values being more desirable. The AIC, BIC, and RSE were 492, 497, and $54 ; 400,406$, and $0.01 ; 381,394$, and 0.02 ; and 380 , 394, and 0.02 for the constant, linear, exponential, and Michaelis-Menten models, respectively. Clearly, the constant representation (i.e., no effect of feeding rate on plasma [GLP-2]) showed the poorest fit to the data, 

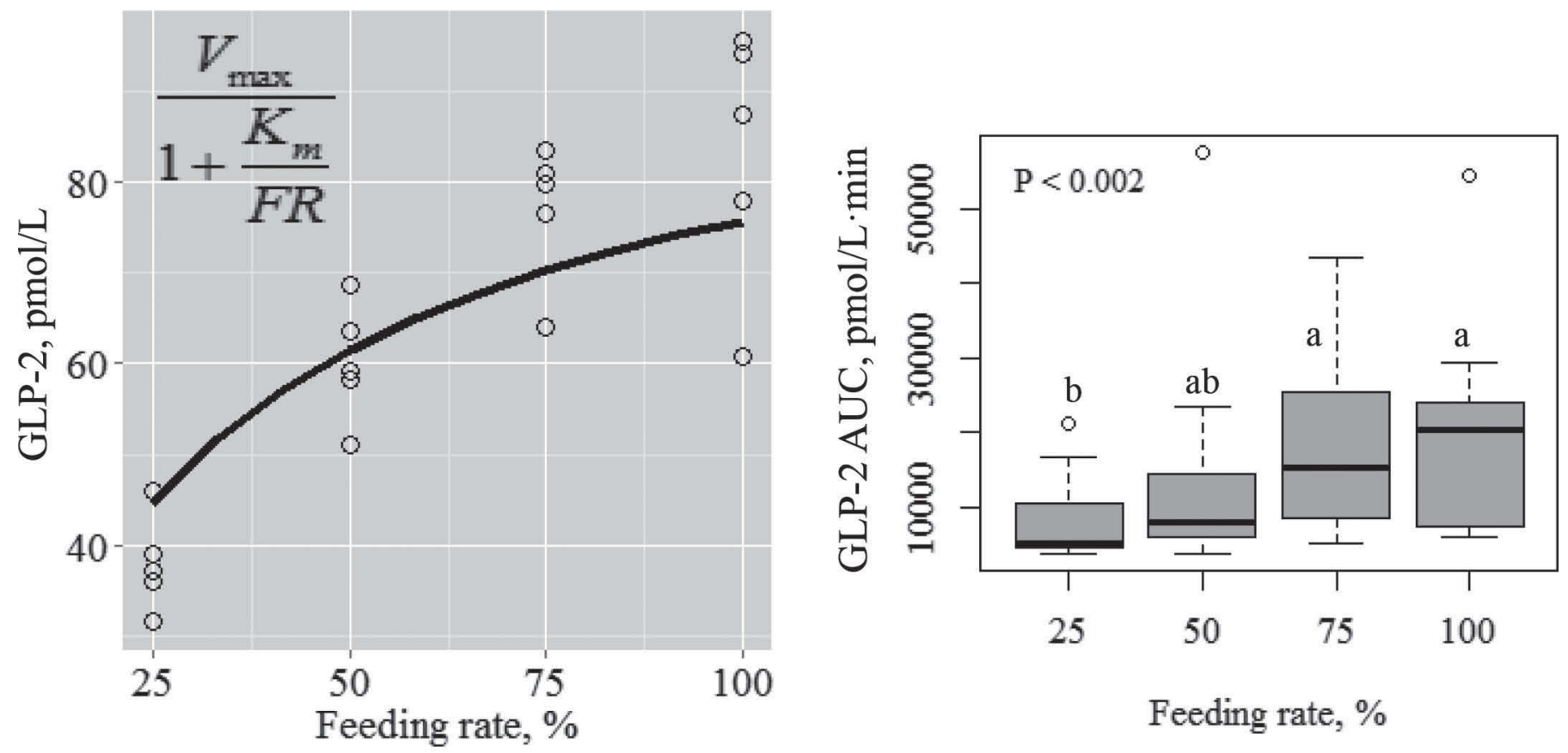

Figure 1. Left panel: Scatter plot of circulating glucagon-like peptide-2 (GLP-2) concentration in response to feeding rate (FR) in milk fed calves in experiment 1 as represented by a Michaelis-Menten equation [maximal plasma GLP-2 concentration $\left(\mathrm{V}_{\max }\right)=98.61$, feeding rate at which GLP-2 plasma concentration reaches half $\mathrm{V}_{\max }\left(\mathrm{K}_{\mathrm{m}}\right)=30.3$ ]. Dots within each feeding rate are means of observations at 15, 30, 60, 90, and 240 min relative to feeding time. Right panel: Effect of feeding rate on the area under the circulating GLP-2 concentration curve (AUC). Lower- and upper-most bars are maximum and minimum values, respectively, excluding outliers; upper and lower box sides are 25th and 75th percentiles, and solid horizontal line is the median or 50th percentile. Groups sharing the same letters do not differ at $P=0.05$.

with the largest AIC, BIC, and RSE, and although the linear model had about the same RSE (0.01 vs. 0.02$)$ as the exponential and Michaelis-Menten models, the latter 2 presented much smaller AIC and BIC values, indicating a better representation of the data despite the large inter-calf variation. Additionally, residual plots for the constant and linear models showed a curvilinear pattern, indicating that a nonlinear component remained unexplained. Because the 2 saturating functions provided similar goodness of fit, the Michaelis-Menten model was retained to explain the effect of feed intake level on [GLP-2] given the biological interpretability of its parameters. Naturally, newborn calves can consume milk at rates greater than $1.75 \%$ of their BW as DM and, as a result, could reach higher plasma GLP-2 concentrations than we found or estimated using the asymptotic value of the Michaelis-Menten model. Hence, data modeling was only intended to explain observations reported herein. To assess whether such saturating response differed between supplemented treatments (i.e., the dependence of feeding rate on type of supplement), we tested whether the affinity constant and maximal velocity parameters were different among supplemented groups following methodology presented elsewhere (Ritz and Streibig, 2008). In addition, the area under the curve (AUC) for GLP-2 secretion after feeding was calculated for each calf and statistically tested for the effects of feeding rate, supplement, and their interaction, adjusting for prefeeding basal GLP-2 plasma concentration.

Milk intake measurements for each calf were averaged and analyzed according to a completely randomized experimental design including the effect of feeding rate and supplementation. Initial BW was included as a covariate:

$$
\begin{aligned}
Y_{i j}= & \text { mean }+B W+{\text { feeding } \text { rate }_{i}+\text { supplement }_{j}} \\
& +\left(\text { feeding rate } \times \text { supplement }_{i j}+e_{i j},\right.
\end{aligned}
$$

where mean is the overall sample mean, $B W$ is the initial $\mathrm{BW}$, and $e_{i j}$ is the deviation of each calf from the mean.

Residuals from both nonlinear and linear models were checked by visual inspection of residual plots and extended Levene tests (Littell et al., 2006), and the homogeneity of variance and normality assumptions were met. The GLP-2 concentrations presented heterogeneous variance and thus the assumption of constant variance was replaced by a power function of the predicted values. The AUC treatment means were 
compared by Tukey's pairwise comparison test. Nonlinear regression analysis was performed with the open source software R (R Development Core Team, 2011) using the package nlme (Pinheiro et al., 2015).

\section{Experiment 2}

Treatment Allotment. Thirty newborn Holstein male calves were acquired in 2 batches from the same source as in experiment 1 . The same prophylactic and biosecurity protocols from experiment 1 were applied. Complete blocks of calves were made based upon BW and, within each block, 1 of the following 3 supplement treatments was randomly assigned $(\mathrm{n}=10)$ to each calf: (1) control (commercial milk replacer), (2) control plus glucose $(220 \mathrm{mg} / \mathrm{kg}$ of BW daily), and (3) control plus $3-\mathrm{O}-\mathrm{M}-\mathrm{G}$ (6 mg/kg of BW daily).

In this experiment, the adaptation and treatment periods were as follows. Calves were fed twice daily at a rate of $1.25 \%$ of $\mathrm{BW}$ (DM basis) daily divided into 2 feedings for the first $2 \mathrm{~d}$. On $\mathrm{d} 3$, the amount of milk replacer was increased to $1.75 \%$ of $\mathrm{BW}$ and then held constant through the end of the experiment. On d 7, glucose supplementation treatments were introduced and continued until the end of experiment at d 22 of age, when calves were harvested. Milk replacer intake was measured daily and averaged by week for each calf. Milk replacer fed was the same as in experiment 1 .

Plasma GLP-2. On d 12, calves were fitted with catheters in the jugular vein for blood sampling. On d 13, jugular venous samples were taken at $-30,0$, $5,15,30,60,120$, and $240 \mathrm{~min}$ relative to feeding for measurement of GLP-2 concentrations. Blood samples were collected into tubes containing EDTA plus pyrrolic acid-based dipeptidyl peptidase 4 inhibitor (cata$\log$ \# DPP4, Millipore). Samples were processed as in experiment 1 . Preserved plasma samples were analyzed for GLP-2 in the same manner as in experiment 1.

Animal Harvest and Sample Collection. On d 22 of the experiment, calves were euthanized with an intravenous injection of pento-barbituric acid $(1 \mathrm{~mL} / 8$ $\mathrm{kg}$ of BW). Samples from fore stomach, small intestine, and hindgut were collected immediately for various analyses as explained below. Digesta was manually removed and the weight and length of intestinal organs was recorded.

Histomorphology. Sections of rumen (dorsal, ventral, proximal, and distal); duodenum; jejunum; ileum; and proximal, middle, and distal colon were collected and fixed in $10 \%$ formalin for $24 \mathrm{~h}$, embedded in paraffin blocks, and stained with hematoxylin and eosin. Paraffin sections ( $5 \mu \mathrm{m}$ thick) were cut and mounted onto glass slides, which were then scanned through a Nanozoomer microscopic scanner (Hamamatsu Pho- tonics, Hamamatsu, Japan) at $40 \times$ to obtain digital scans on which papillae and villi height and width, and crypt width and depth were measured afterward.

Cellular Proliferation. Abundance of labeled cell nuclei with the protein marker Ki67 in paraffin-embedded tissue sections from jejunum, ileum, and colon was measured as a proxy for cell proliferation following the manufacturer's instructions (Vector Labs, Burlingame, CA). After immunostaining, the abundance of Ki-67 was assessed by scanning the slides on a Nanozoomer microscope (Hamamatsu Photonics) at $40 \times$ to obtain digital microscopic scans. The digital image processing software AxioVision (Zeiss, Oberkochen, Germany) was used to compute the Ki-67-stained area based on a predefined pixel intensity on the microscopic scans.

$m \boldsymbol{R} N \boldsymbol{A}$ Expression. Epithelium scrapings from ileum and colon were collected into RNALater reagent (Qiagen, Hilden, Germany) to assess treatment effects on mRNA expression of genes related to the GLP-2 paracrine signaling pathway and functional or developmental traits.

For mRNA extraction, tissue was homogenized in ice-cold Trizol using a bead beater (Invitrogen Corp., Carlsbad, CA). Afterward, extraction with acid-phenol chloroform was performed (Ambion, Austin, TX). Purification of mRNA and genomic DNA removal was carried out through a mRNAeasy mini kit (Qiagen) and incubation with DNase. The mRNA integrity was evaluated using an Agilent 2100 Bioanalyzer (Agilent Technologies, Palo Alto, CA). The RNA integrity was considered satisfactory when sample score was 6 or greater. Procedures to perform cDNA synthesis and quantitative reverse transcription PCR were as described previously (Ji et al., 2014).

Gene expression was normalized using the geometric mean of 3 internal control genes validated as stable internal control genes following methodology presented elsewhere (Vandesompele et al., 2002): glyceraldehyde 3-phosphate dehydrogenase $(G A P D H), \beta-2-$ microglobulin $(B 2 M)$, and hypoxanthine phosphoribosyltransferase 1 (HPRT1); B2M and HPRT1 have been used previously in calves (Connor et al., 2010).

Genes selected to represent the GLP-2 pathway were proglucagon $(G C G)$ and GLP-2 receptor (GLP2R; Connor et al., 2010). Genes selected to represent the GLP-2 paracrine mediator network (Rowland and Brubaker, 2011) included keratinocyte growth factor $\left(F G F^{\text {m}}\right)$, endothelial nitric oxide synthase (NOS3), IGF-1 and IGF-2 (IGF1, IGF2), IGF1 receptor $(I G F 1 R)$, vasoactive intestinal peptide $(V I P)$, epidermal growth factor receptor $(E G F R)$, heparin binding EGF-like growth factor $(H B E G F)$, early growth response 1 (EGR1), c FOS proto-oncogene (FOS), and neuregulin 1 (NRG1). Genes thought to be involved in the GLP-2 cellular 
signaling cascade (Rowland and Brubaker, 2011) were murine thymoma viral oncogene $(A K T 1)$ and phosphatidylinositol 3 biphosphate kinase (PIK3CA). In addition, a few previously reported functional marker genes were evaluated (Connor et al., 2010). For peptide transport, cell apoptosis, and cell proliferation, the expression of genes encoding for the solute carrier family (SLC15A1), caspase 6 (CASP6), and proliferating cell nuclear antigen (PCNA) as well as cyclin D1 (CCND1), respectively, was assessed.

Primers were designed using Primer Express 3.0 (Applied Biosystems, Carlsbad, CA) with amplicon size between 80 and $120 \mathrm{bp}$ where possible. Pooled intestinal cDNA was used to test primers by running them in a $2 \%$ agarose gel. If a band of expected size was present in the gel, the amplicon was submitted for sequencing to the core DNA sequencing facility at Roy J. Carver Biotechnology Center at the University of Illinois (Urbana) and the sequencing results were searched using BLAST (http://blast.ncbi.nlm.nih.gov/Blast.cgi) to verify the primer specificity. Forward and reverse primers are presented in Table 1.

Gene PCR amplification efficiency (Table 2) was calculated from the standard curve as follows:

$$
\text { Efficiency }=-10^{\left(\frac{-1}{\text { Slope }}\right)} \text {. }
$$

Then, mRNA abundance was computed as follows:

$$
\text { mRNA abundance }=\frac{1}{(\text { Efficiency })^{\Delta C t}}
$$

where $\Delta C t=\left[C t_{\text {sample }}-\right.$ (geometric mean of internal control genes)], and $C t=$ cycle threshold. The sequence of amplicons obtained from the primers was verified against the National Center for Biotechnology Information (NCBI) primer BLAST tool (https://blast.ncbi. nlm.nih.gov/Blast.cgi) and are presented in Table 3.

Statistical Analysis. For milk intake, the model of variance analysis included treatment, week as a repeated measure, and their interaction as fixed effects. Initial BW was included as a covariate. Calf batch was included as a block but dropped from the model due to nonsignificance. Different error structures among repeated measures were evaluated and the one that minimized the adjusted and unadjusted AIC (AAIC and AIC), BIC, and -2 Ratio Log-likelihood, with the least number of parameters, was chosen. The model was

$$
\begin{gathered}
Y_{i j k}=\text { mean }^{+} B W+\text { supplement }_{i}+E_{i j}+\text { week }_{k} \\
+(\text { supplement } \times \text { week })_{i k}+e_{i j k},
\end{gathered}
$$

where mean is the overall mean, $B W$ is the initial $\mathrm{BW}$, supplement $_{i}$ is the effect of glucose or $3-\mathrm{O}-\mathrm{M}-\mathrm{G}$ supplementation, week $k_{k}$ is the effect of time, (supplement $\times$ week $)_{i k}$ is the effect of the interaction, and $E_{i j}$ and $e_{i j k}$

Table 1. Gene identification, accession number, and corresponding forward and reverse verified primers in experiment 2

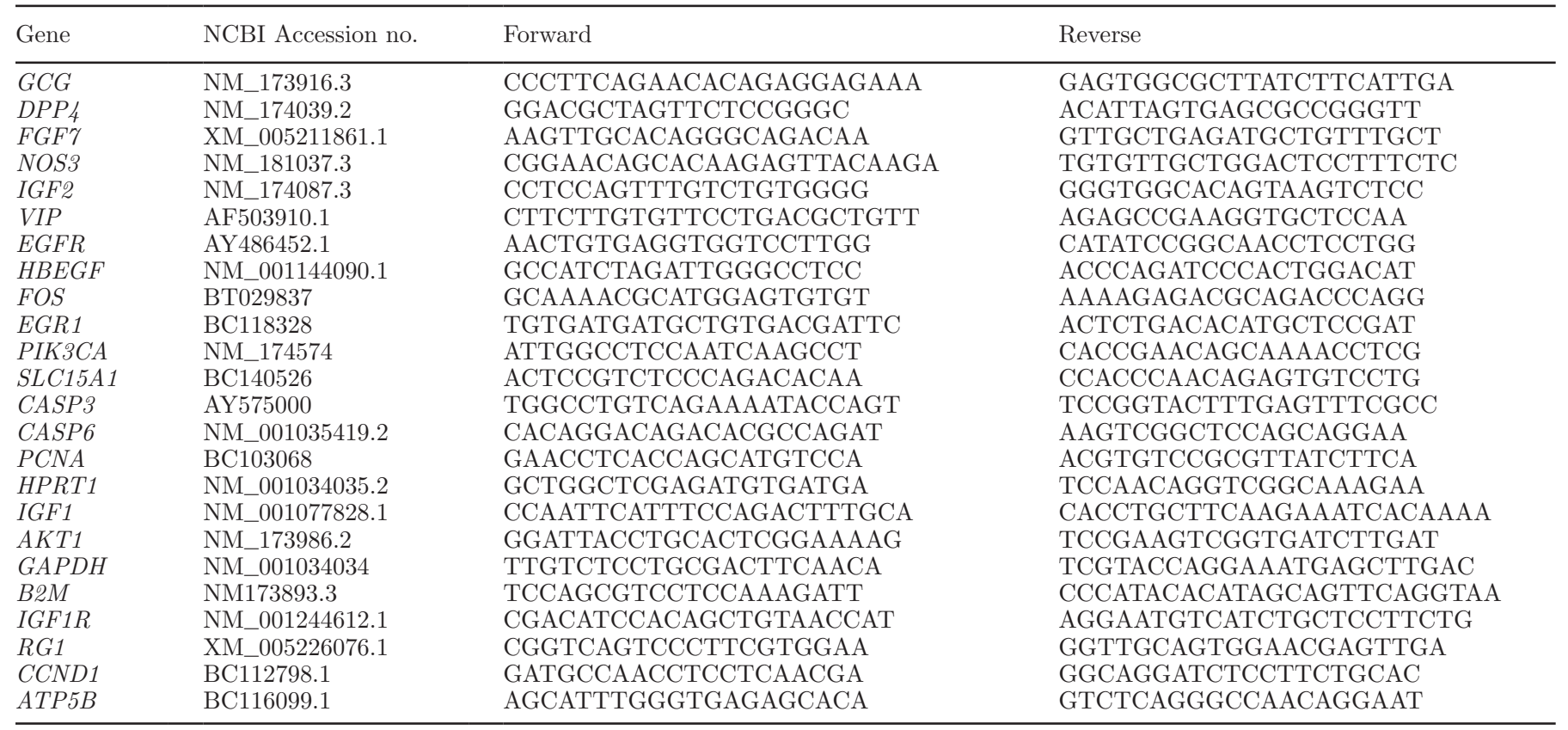


Table 2. Reverse transcription quantitative PCR performance for all genes measured in ileum and colon in experiment $2^{1}$

\begin{tabular}{|c|c|c|c|c|c|}
\hline Gene & Ct median & Median $\Delta \mathrm{Ct}$ & Slope & $\mathrm{R}^{2}$ & Efficiency \\
\hline$G C G$ & 23.76 & 3.52 & -3.28 & 0.99 & 2.01 \\
\hline$E G F R$ & 24.81 & 4.70 & -3.27 & 0.99 & 2.02 \\
\hline EGR1 & 24.14 & 4.13 & -3.29 & 0.99 & 2.01 \\
\hline$F G F^{r 7}$ & 27.63 & 7.37 & -2.87 & 0.99 & 2.23 \\
\hline$F O S$ & 24.42 & 4.39 & -3.31 & 0.98 & 2.00 \\
\hline$A K T 1$ & 21.32 & 1.34 & -2.91 & 0.97 & 2.20 \\
\hline CASP 6 & 21.43 & 1.34 & -3.29 & 0.99 & 2.01 \\
\hline$H B E G F$ & 27.75 & 7.79 & -2.96 & 0.98 & 2.17 \\
\hline$I G F 1$ & 26.16 & 6.12 & -3.01 & 0.99 & 2.14 \\
\hline$I G F-2$ & 23.90 & 3.73 & -3.10 & 0.99 & 2.10 \\
\hline NOS3 & 25.71 & 5.45 & -3.07 & 0.99 & 2.11 \\
\hline$P C N A$ & 22.74 & 2.53 & -3.35 & 0.99 & 1.98 \\
\hline PIK $3 C A$ & 24.49 & 4.41 & -3.42 & 0.98 & 1.95 \\
\hline SLC15A1 & 22.81 & 2.98 & -3.07 & 0.98 & 2.11 \\
\hline$V I P$ & 29.58 & 9.45 & -2.95 & 0.99 & 2.17 \\
\hline$A T P 5 B$ & 19.96 & 0.12 & -3.26 & 0.99 & 2.02 \\
\hline$C C N D 1$ & 24.93 & 4.82 & -3.52 & 0.99 & 1.92 \\
\hline$I G F 1 R$ & 24.88 & 4.69 & -3.29 & 0.99 & 2.01 \\
\hline$N R G 1$ & 26.24 & 6.14 & -3.20 & 0.99 & 2.05 \\
\hline$G L P 2 R$ & 25.31 & 5.18 & -2.92 & 0.99 & 2.20 \\
\hline
\end{tabular}

${ }^{1} \mathrm{Ct}$ median $=$ median cycle threshold $(\mathrm{Ct})$ from all ileum and colon samples from 45 calves; slope and $\mathrm{R}^{2}=$ slope and coefficient of determination of the standard curve.

are the error between calves within the same treatment and the error between repeated measures for the same calf, respectively.

Similarly, for GLP-2 concentrations over time, the model included treatment, hour as a repeated measure, and their interaction as fixed effects. Error correlation structure among repeated measures was evaluated as mentioned above. The model was

$$
\begin{aligned}
Y_{i j k}= & \text { mean }+ \text { supplement }_{i}+E_{i j}+\text { hour }_{k} \\
& +(\text { supplement } \times \text { hour })_{i k}+e_{i j k},
\end{aligned}
$$

Table 3. Sequence of amplicons obtained from primers and verified against the National Center for Biotechnology Information primer BLAST (https://blast.ncbi.nlm.nih.gov/Blast.cgi) in experiment 2

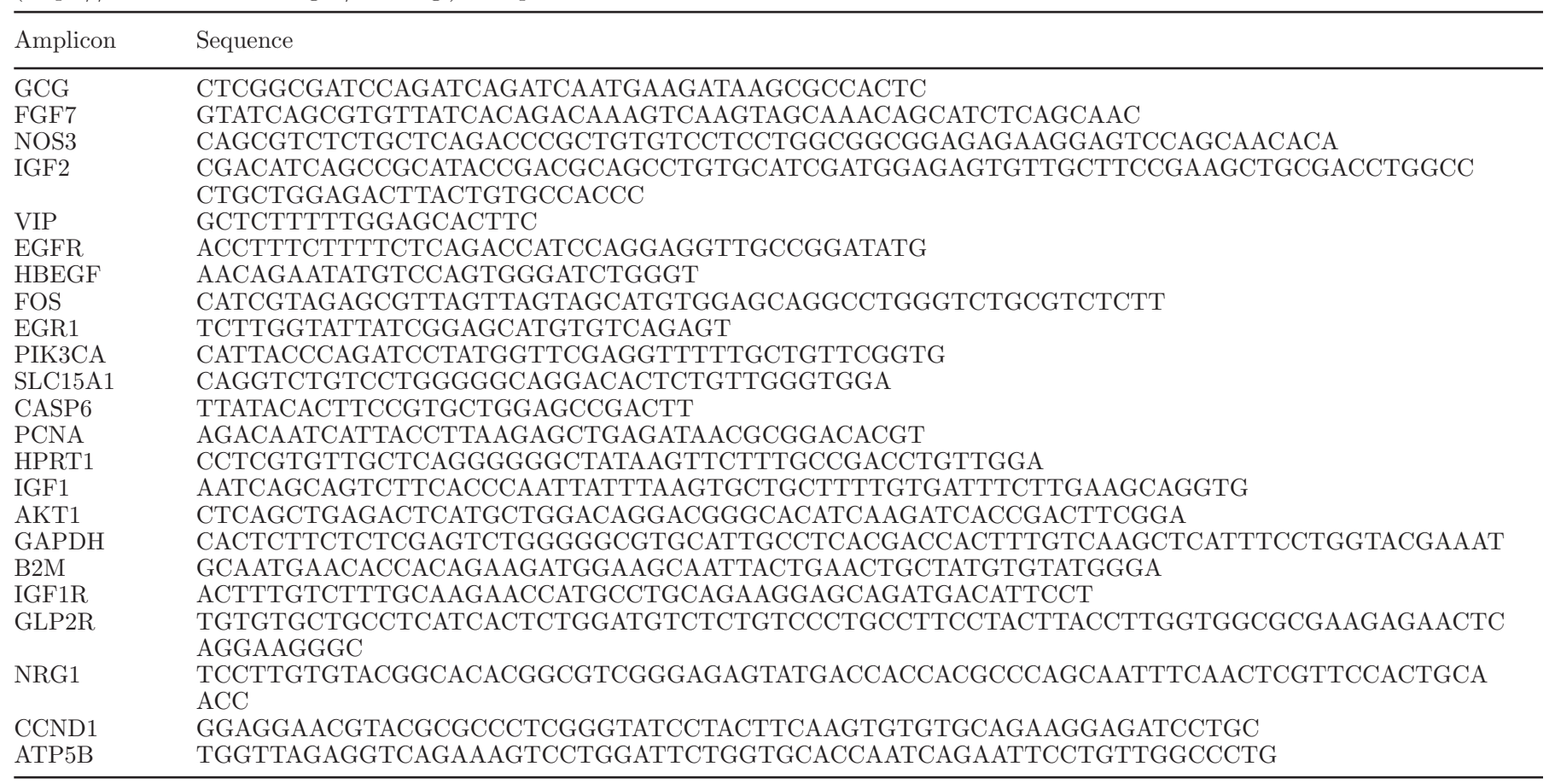


where mean, supplement, hour, and their interaction represent the overall mean and the respective linear effects, and $E_{i j}$ and $e_{i j k}$ are the error between calves within the same treatment and the error between repeated measures for the same calf, respectively.

A similar statistical linear model for nonindependent observations was used for gastrointestinal organ size, histomorphology, and cellular proliferation measures because repeated measures were performed on various anatomical regions of the same calf. The AUC for GLP-2 secretion was computed and compared among treatments in a one-way ANOVA.

Residuals were checked for homogeneity of variance and normality assumptions by residual plots and extended Levene test. Heterogeneous variances were handled by implementing error structures that allow for heterogeneous variances (Littell et al., 2006).

To account for potential correlations in the mRNA abundance from 21 genes that were measured simultaneously, a permutational multivariate ANOVA (PERMANOVA; Anderson, 2001) was conducted on a Euclidean distance matrix built from the standardized variables (mean $=0, \mathrm{SD}=1)$ to test the hypothesis of an overall effect of supplement or intestinal section (i.e., ileum vs. colon) on overall gene expression. The model included effects of additive supplementation, intestinal section within calf, their interaction, and calf batch. In addition, a principal component analysis (PCA) ordination was used to visually identify treatment or organ site differences, taking all genes into account simultaneously, and to determine what genes drive the most variation in signaling pathway in ileum and colon (Johnson, 1998).

Repeated-measures analyses were performed using PROC MIXED (SAS Institute Inc., 2011). Multivariate analysis of gene expression data was carried out with the VEGAN (Oksanen et al., 2012) and STATS packages in $\mathrm{R}$ open source software ( $\mathrm{R}$ Development Core Team, 2011).

\section{RESULTS}

\section{Experiment 1}

In total, 46 calves completed the trial. Two calves were not sampled on d 8 because of health issues. One of the calves not sampled was on the $50 \%$ feeding rate plus 3-O-M-G treatment and the other was on the $100 \%$ feeding rate plus glucose.

Milk Intake. As designed, there was a significant effect of feeding rate on milk replacer intake $(P<$ $0.001)$. We detected no effect of glucose or $3-\mathrm{O}-\mathrm{M}-\mathrm{G}$ supplementation on milk replacer intake $(P<0.98$; Table 4). Given the observed DMI and the $44 \%$ lactose
Table 4. Least squares treatment means for milk intake on $\mathrm{d} 6,7$, and 8 in experiment 1

\begin{tabular}{lcc}
\hline Variable & Milk DMI, kg/d & $P$-value \\
\hline Feeding rate & $0.193 \pm 0.009^{\mathrm{d}}$ & $<0.0001$ \\
$25 \%$ & $0.392 \pm 0.01^{\mathrm{c}}$ & \\
$50 \%$ & $0.608 \pm 0.009^{\mathrm{b}}$ & \\
$75 \%$ & $0.824 \pm 0.01^{\mathrm{a}}$ & \\
$100 \%$ & $0.50 \pm 0.06$ & \\
Supplement ${ }^{1}$ & $0.49 \pm 0.06$ & \\
Control $_{\text {Glucose }}$ & $0.51 \pm 0.06$ & \\
3-O-M-G & & \\
\hline
\end{tabular}

${ }^{\mathrm{a}-\mathrm{d}}$ Means within a column with different superscripts indicate statistical difference.

${ }^{1}$ Control treatment $=$ commercial milk replacer without supplementation; glucose $=$ commercial milk replacer plus glucose $(220 \mathrm{mg} / \mathrm{kg}$ of $\mathrm{BW}$ daily), and 3-O-M-G = commercial milk replacer plus 3-O-methyl glucose $(6 \mathrm{mg} / \mathrm{kg}$ of BW daily).

concentration of the milk replacer used, total glucose plus galactose intake from milk would have been about $85,173,268$, and $363 \mathrm{~g} / \mathrm{d}$ for feeding rates of $0.44,0.88$, 1.3 , and $1.75 \%$ of BW as DM, respectively.

GLP-2 Concentrations in Plasma. A MichaelisMenten equation (Figure 1, left panel) provided the best description of plasma [GLP-2] in response to the increasing feeding rate compared with a constant (i.e., no relationship) or a linear representation (i.e., linear increase in plasma [GLP-2] with feeding rate), as indicated by AIC, BIC, and residual plots, its parameter estimates $\mathrm{V}_{\max }$ and $\mathrm{K}_{\mathrm{m}}$ being different from zero $(P<$ 0.01 ), and the model residuals following the NIID $\left(0, \sigma^{2}\right)$ assumptions. In the Michaelis-Menten equation, $\mathrm{V}_{\max }$ is the maximum potential GLP-2 secretion that would be attained at an extremely large feed intake and was estimated to be $98.61 \mathrm{pmol} / \mathrm{L}$; the affinity constant $\mathrm{K}_{\mathrm{m}}$ (i.e., the feeding rate required to reach $50 \%$ of $\mathrm{V}_{\max }$ ) was estimated at $30.3 \pm 9.5 \%$ equivalent to approximately $0.45 \%$ of BW on a DM basis (Figure 1, left panel). Visual appraisal of Figure 1 (left panel) suggests that at a feeding rate of $100 \%$, a plateau in peptide secretion was approximated; thus, feed intakes above $1.75 \%$ of $\mathrm{BW}$ as $\mathrm{DM}$ could result in marginally smaller increases in GLP-2 secretion. If we considered the AUC for GLP-2 secretion among the various feeding rate treatments (Figure 1, right panel), we observed a wide variation for the $75 \%$ feeding rate in particular and 3 extreme observations, one in each of the 25, 50, and $100 \%$ feeding rate groups. Because these were not considered faulty data, they remained in the statistical analysis and were not leveraged up- or downward. The estimated AUC means for the 25, 50, 75, and $100 \%$ rates were $9,629,14,188,17,181$, and $19,790 \mathrm{pmol} /$ L.min, respectively, indicating a numerical increment as feed intake increased. Taking the AUC for the $100 \%$ 


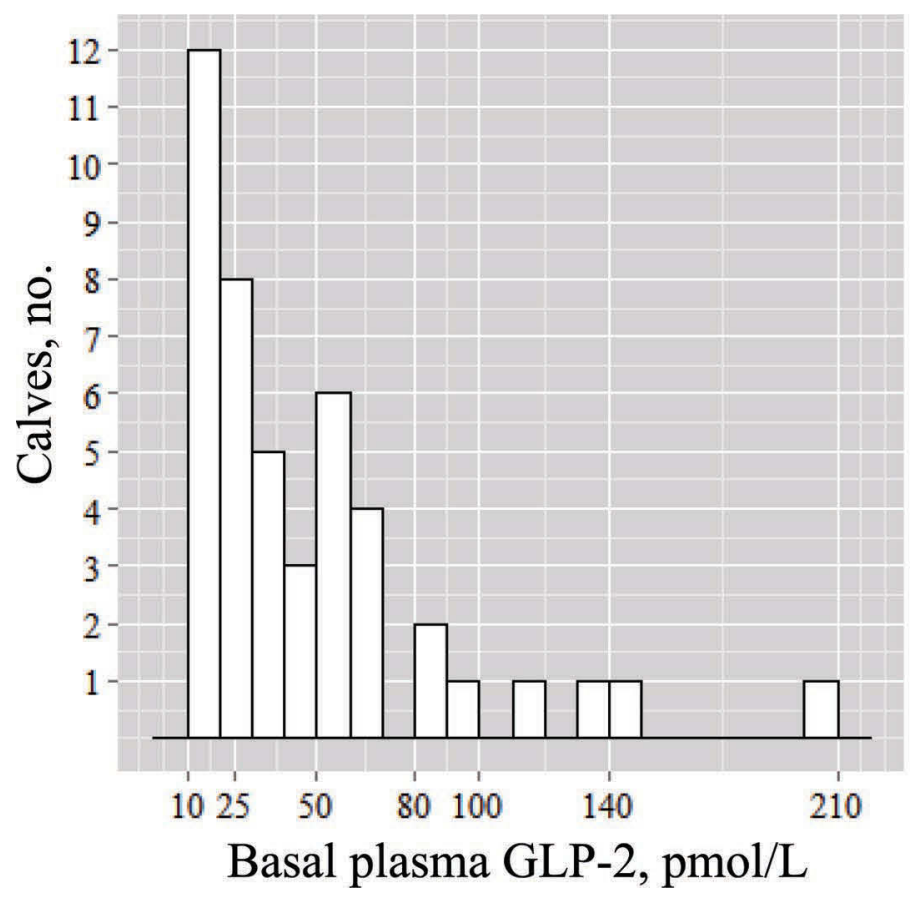

$$
V \max =8.7+1.9( \pm 0.3) \times[\mathrm{GLP}-2]_{\mathrm{Basal}}
$$

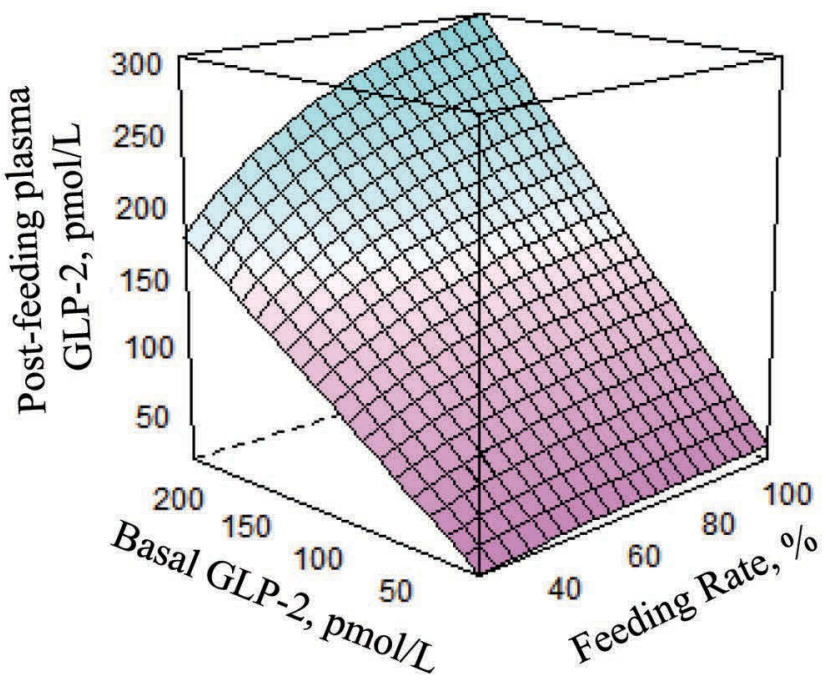

Figure 2. Distribution of basal (i.e., prefeeding) plasma glucagon-like peptide-2 (GLP-2) concentrations (left panel) in experiment 1. Predicted relationship between basal plasma GLP-2 levels and feeding rate with postfeeding GLP-2 plasma concentrations (right panel; $\mathrm{V}_{\text {max }}=$ maximal plasma GLP-2 concentration). Color version available online.

feeding rate as reference, calves in the 75,50 , and $25 \%$ feeding rate treatments reached 87,72 , and $49 \%$ of the maximal GLP-2 level. The difference between the AUC for the 75 and $100 \%$ groups was not statistical and nor was the difference between groups 75 and $50 \%$. The AUC for the $25 \%$ group was significantly lower than that achieved by the 75 and $100 \%$ feeding rates but was not different from 50\% (Figure 1, right panel). It appears, therefore, that a feeding rate of $50 \%$ of standard or $0.875 \%$ of $\mathrm{BW}$ on a DM basis was the threshold rate from which further reductions in the amount of milk fed down to $25 \%$ resulted in both numerical and statistical decreases in the circulating concentration of GLP-2 (Figure 1, right panel).

It is important to highlight, however, that inter-calf variation was large (Figure 1, left panel) and although a saturating response of plasma [GLP-2] to milk intake explains the data best, a large portion of the residual variation is likely to be explained by unknown calf specific traits.

Indeed, further examination of the data indicated that the maximal response in plasma GLP-2 concentration (i.e., $\mathrm{V}_{\max }$ ) to milk intake had a strong linear dependency on the calf-specific basal prefeeding concentration of the peptide in plasma ( $<0.0001$; Figure 2, right panel). In the observed range of basal concentrations from about 10 to $210 \mathrm{pmol} / \mathrm{L}$ (Figure 2, left panel), plasma GLP-2 was estimated to increase linearly from below 50 to almost $200 \mathrm{pmol} / \mathrm{L}$ at low feeding rates, whereas at a feeding rate of $100 \%$, GLP-2 was estimated to reach about $300 \mathrm{pmol} / \mathrm{L}$ (Figure 2, right panel). The effect of basal prefeeding levels on postprandial GLP-2 secretion was reflected in the AUC. In Figure 3, both an exploratory nonparametric fit (solid line) and the actual linear regression (dashed line) indicate the strong positive relationship $(P<$ $\left.0.0001, \mathrm{R}^{2}=0.8\right)$ between basal concentrations and the GLP-2 AUC. Thus, for each unit increase in basal plasma GLP-2, we detected an approximate estimated increase of $241 \pm 20$ units in AUC (pmol/L·min).

To discern whether such a strong effect of basal GLP2 plasma concentration was an indirect consequence of the feeding rate or supplement treatments, we conducted a 2-way ANOVA, whose results are presented in Figure 4. It is visually apparent that neither of the 2 factors affected basal plasma GLP-2 concentration given the large overlap in the data distribution of both feeding level $(P>0.8)$ and supplemental glucose $(P$ $>0.5)$ groups, which was statistically confirmed at a type 1 error rate of $5 \%$ (Figure 4, left and right panels). Given that all other experimental conditions were similar among calves, this implies that calf intrinsic characteristics determine the basal GLP-2 secretion and hence a large portion of the postfeeding response.

With respect to the hypothesis that glucose supplementation could directly or through an interaction with 


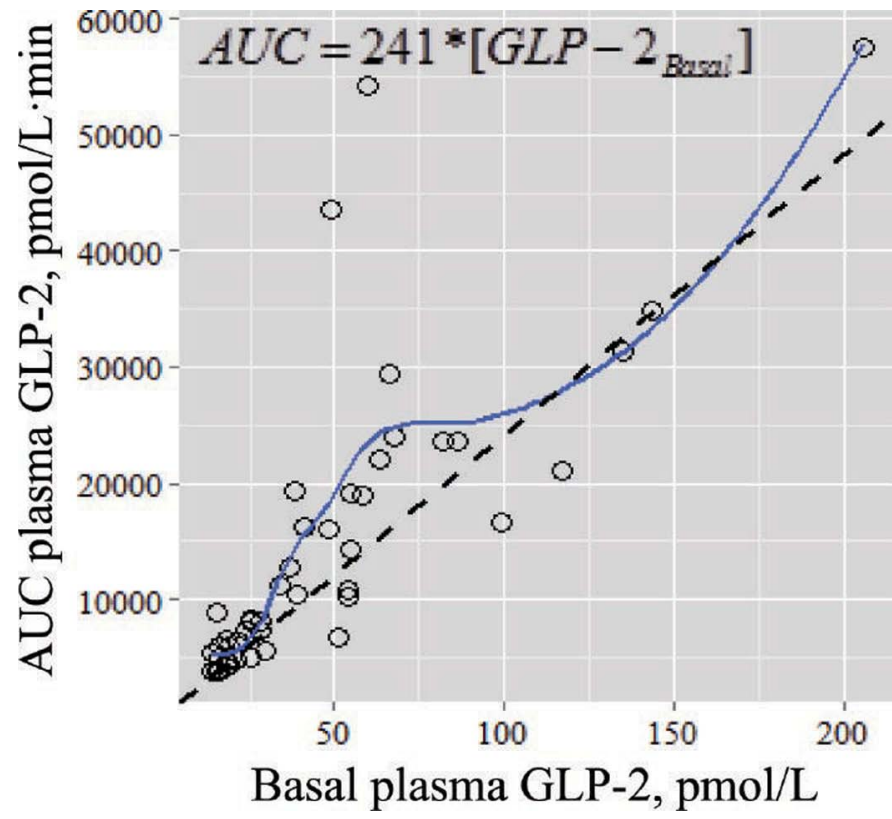

Figure 3. Relationship between basal (i.e., prefeeding) plasma glucagon-like peptide-2 concentration [GLP-2] and area under concentration curve (AUC) in experiment 1. $P<0.0001, \mathrm{R}^{2}=0.8$. Dashed line corresponds to linear fit $\left(\mathrm{AUC}=241 \times\left[\mathrm{GLP}-2_{\text {basal }}\right)\right.$, whereas the solid line represents the nonparametric Loess fit. Color version available online.

feeding rate affect GLP-2 secretion (Figure 5), we detected a tendency $(P<0.09)$ for glucose-supplemented calves to have a lower $\mathrm{V}_{\max }(94 \mathrm{pmol} / \mathrm{L})$ compared with control calves (101 pmol/L; Figure 5, left panel). This would suggest that glucose-supplemented calves presented a lower release of GLP-2. Control calves and 3-O-M-G calves did not differ in $\mathrm{K}_{\mathrm{m}}$ or $\mathrm{V}_{\max }$. To determine whether this difference in maximal GLP-2 concentration in response to supplements translated into a difference in total peptide secretion over time, the AUC was compared among treatments. As shown in Figure 5 (right panel), the difference among the control, glucose, and $3-\mathrm{O}-\mathrm{M}-\mathrm{G}$ treatment groups was not significant $(P$ $<0.36)$. Furthermore, the interaction between feeding rate and supplementation for the AUC also was not significant $(P<0.6)$.

\section{Experiment 2}

Feed Intake. Average milk DM intake was not different among control, glucose, and 3-O-M-G supplemented calves $(P<0.33)$, and no interaction between supplementation and time $(P<0.37)$ was evident (Table 5).

GLP-2 Secretion. We observed no effect of treatment $(P<0.51)$ or its interaction with time postfeeding $(P<0.95)$ on average plasma GLP-2 concentration with respect to the control diet. Also, we did not $(P<$ 0.52 ) observe an effect of supplement type on the AUC for GLP-2 secretion (Table 6).

Rumen and Intestine Size. Addition of glucose or 3-O-M-G to the milk replacer did not affect organ weight, expressed either in kilograms $(P<0.35)$ or as a percentage of BW $(P<0.39)$ or organ length $(P<$ $0.41)$. The interaction between treatment and intestinal organ was also not statistically significant $(P>0.5$; data not shown).

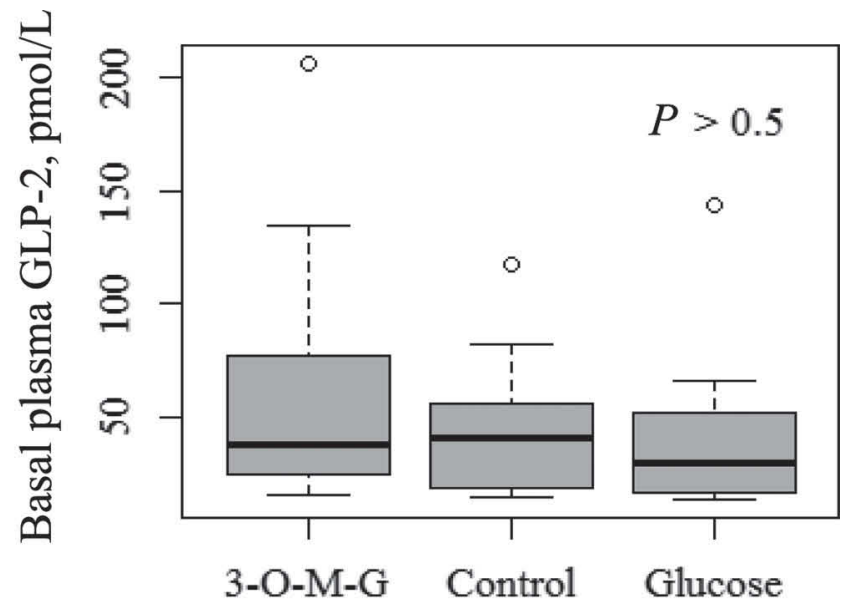

Supplement

Figure 4. Effect of feeding rate (left panel) and supplement type (right panel) on basal (i.e., prefeeding) plasma glucagon-like peptide-2 (GLP-2) concentrations ( $\mathrm{pmol} / \mathrm{L})$ in experiment 1. 3-O-M-G $=3-\mathrm{O}-$ methyl glucose. Lower- and upper-most bars are maximum and minimum values, respectively, excluding outliers; upper and lower box sides are 25th and 75th percentiles, and solid horizontal line is the median or 50th percentile. 
Table 5. Least squares treatment means for milk intake in experiment 2

\begin{tabular}{|c|c|c|c|c|c|c|}
\hline \multirow[b]{2}{*}{ Item } & \multicolumn{3}{|c|}{ Treatment $^{1}$} & \multirow[b]{2}{*}{$\mathrm{SE}$} & \multicolumn{2}{|c|}{$P$-value ${ }^{2}$} \\
\hline & Control & Glucose & 3-O-M-G & & Trt & Trt $\times$ week \\
\hline Milk DMI, $\mathrm{kg} / \mathrm{d}$ & 0.7 & 0.69 & 0.71 & 0.008 & 0.33 & 0.37 \\
\hline
\end{tabular}

Epithelium Morphometric Dimensions. The length and width of the rumen papillae $(P<0.45)$; the length $(P<0.84)$ and width $(P<0.83)$ of the villi in the duodenum, jejunum, and ileum; and crypt depth $(P<0.49)$ and width $(P<0.20)$ in duodenum, jejunum, ileum, and colon were similar across the control, glucose, and 3-O-M-G groups. No interaction of treatments with intestinal section was detected $(P>$ 0.50; data not shown).

Cellular Proliferation. The average abundance of Ki-67-stained nuclei did not differ among control, glucose, and $3-\mathrm{O}-\mathrm{M}-\mathrm{G}$ treatments $(P<0.16)$, and this lack of effect $(P<0.20)$ was consistent across intestinal sections (data not shown).

Gene Expression of the GLP-2 Signaling Pathway. The PERMANOVA indicated that simultaneous expression of all genes involved in the GLP-2 signaling pathways (Table 7) was not affected $(P<$ 0.68 ) by glucose or $3-\mathrm{O}-\mathrm{M}-\mathrm{G}$ supplementation or the interaction with the intestinal sections (i.e., ileum and colon). Therefore, comparisons between treatments for specific genes are not reported. In contrast, simultaneous expression for all genes differed significantly $(P<$ 0.014 ) between ileum and colon (Table 7 ). To identify which genes caused the most variation in this system, we followed the PERMANOVA with a PCA. Figure 6 displays the first 2 principal components, which together accounted for $\sim 75.3 \%$ of the variation in gene expression. All treatment groups clustered together with full overlap (Figure 6, left panel), whereas ileum and colon samples clustered distinctly apart (Figure 6, right panel). Principal component 1 (PC1) explained most of the variation $(66 \%)$ in gene expression related to the GLP-2 pathway. The genes driving such variation were EGFR, AKT1, NOS3, NRG1, GLP2R, and $I G F 1 R$, as indicated by a high positive correlation with $\mathrm{PC} 1$, and were associated with colon samples, whereas SLC15A1 and PCNA were negatively correlated with PC1and were associated with ileum samples (Table 8). These associations set forward for consideration that the GLP-2 signaling cascade is better established in the colon than in the ileum of calves. In summary, neither glucose nor 3-O-M-G appeared to elicit any effects on GLP-2 secretion, intestinal development, or gene expression.

\section{DISCUSSION}

The present data indicate that GLP-2 secretion responds in a saturating manner to nutrient intake in young calves. We found that the marginal response in GLP-2 secretion diminished when the feeding rate exceeded $75 \%$ of the maximum (i.e., $1.32 \%$ of BW as DM), eventually reaching a plateau as indicated by similar AUC values for the 75 and $100 \%$ feeding rates. Feeding 75,50 , and $25 \%$ of the maximal feed intake (i.e., $1.75 \%$ BW as DM) resulted in plasma GLP-2 concentrations that were 87,72 , and $49 \%$ of that in fully fed calves, which is quantitatively similar to previous observations in piglets (Burrin et al., 2000). The amount of food delivered to the intestine is a key regulator of GLP2 secretion and intestinal development (Rowland and Brubaker, 2011). Even when piglets were supplied with the same daily amount of nutrients, enteric adminis-

Table 6. Treatment means for plasma glucagon-like peptide-2 concentration [GLP-2] and area under the curve (AUC) in experiment 2

\begin{tabular}{|c|c|c|c|c|c|c|c|}
\hline Item & \multicolumn{3}{|c|}{ Treatment $^{1}$} & SE & \multicolumn{3}{|c|}{$P$-value ${ }^{2}$} \\
\hline $\begin{array}{l}{[\mathrm{GLP}-2], \mathrm{pmol} / \mathrm{mL}} \\
\text { AUC, } \mathrm{pmol} / \mathrm{mL} \cdot \mathrm{min}\end{array}$ & $\begin{array}{l}38.0 \\
9.204\end{array}$ & $\begin{array}{r}47.0 \\
12.667\end{array}$ & $\begin{array}{l}32.8 \\
8.766\end{array}$ & $\begin{array}{l}10.5 \\
2.905\end{array}$ & $\begin{array}{l}0.51 \\
0.52\end{array}$ & $\begin{array}{l}<0.0001 \\
\mathrm{NA}^{3}\end{array}$ & $\begin{array}{l}0.95 \\
\text { NA }\end{array}$ \\
\hline
\end{tabular}

${ }^{1}$ Control treatment $=$ commercial milk replacer without supplementation; glucose $=$ commercial milk replacer plus glucose $(220 \mathrm{mg} / \mathrm{kg}$ of BW daily), and 3-O-M-G = commercial milk replacer plus 3 -O-methyl glucose $(6 \mathrm{mg} / \mathrm{kg}$ of BW daily).

${ }^{2}$ Trt $=$ treatment effect; Trt $\times$ min $=$ treatment by minute interaction effect.

${ }^{3} \mathrm{NA}=$ not applicable. 

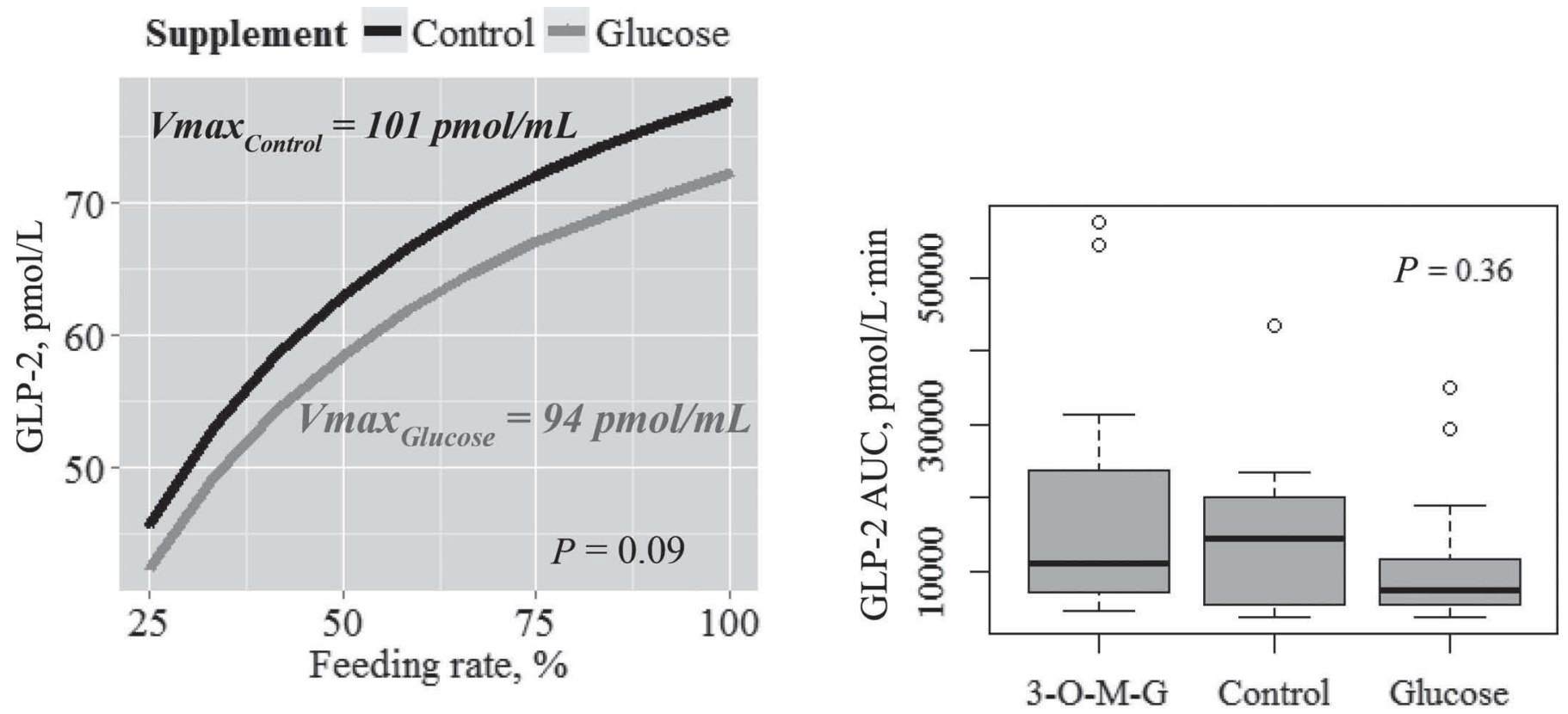

Supplement

Figure 5. Left panel: Difference in glucagon-like peptide-2 (GLP-2) concentration between control and glucose-supplemented milk-fed calves in response to feeding rate $(\mathrm{FR})\left(\mathrm{V}_{\max -\text { Control }}=101 \mathrm{pmol} / \mathrm{L}, \mathrm{V}_{\max -\mathrm{Glucose}}=94 \mathrm{pmol} / \mathrm{L}, \mathrm{K}_{\mathrm{m}}=30.3 \% ; \mathrm{V}_{\max }=\right.$ maximal plasma GLP-2 concentration, $\mathrm{K}_{\mathrm{m}}=$ feeding rate at which GLP-2 plasma concentration reaches half $\mathrm{V}_{\max }$ ) in experiment 1. Right panel: Effect of supplement on area under GLP-2 concentration curve (AUC). 3-O-M-G = 3-O-methyl glucose. Lower- and upper-most bars are maximum and minimum values, respectively, excluding outliers; upper and lower box sides are 25th and 75th percentiles, and solid horizontal line is the median or 50th percentile.

tration of at least $\sim 50 \%$ of the daily food allowance led to enhanced GLP-2 release and intestinal development compared with animals fed enterally. Although the evidence from the study remained circumstantial and other trophic peptides such as IGF-1 might have been involved, it is possible that GLP-2 elicited a large portion of the intestinal growth response (Burrin et al., 2000). In calves, the minimum intake of milk required to achieve sufficient secretion of GLP-2 to maintain intestinal development and function is unknown. This information could be useful to devise successful dietary or therapeutic interventions in certain situations. For instance, diarrhea-ill calves whose nutrient intake com- monly drops well below $1 \%$ of $\mathrm{BW}$ as DM for several days or limit-fed calves whose milk intake frequently ranges between 0.96 and $1.2 \%$ of $\mathrm{BW}$ as $\mathrm{DM}$ over the first 6 to 8 wk of life (Davis and Drackley, 1998) might benefit from exogenous GLP-2 therapy or any dietary intervention that stimulates the release of endogenous GLP-2. Yet, before such alternatives become possible, we have to quantify the causal relationship between the circulating concentration of GLP-2 and specific measures of intestinal growth and function such as organ and epithelial mass, mucosal permeability, nutrient absorption, and local blood flow. Given that food intake is the major driver of GLP secretion, the present study

Table 7. Permutational multivariate ANOVA (PERMANOVA) test for treatment and intestinal section effects on the glucagon-like peptide-2 pathway gene expression in experiment 2

\begin{tabular}{|c|c|c|c|c|c|c|}
\hline Source & df & $\begin{array}{c}\text { Sum of squared } \\
\text { distances }\end{array}$ & Mean square & $F$-value & $\mathrm{R}^{2}$ & $P$-value \\
\hline Calf batch & 1 & 66.63 & 66.63 & 5.46 & 0.06 & 0.002 \\
\hline Treatment & 2 & 27.62 & 13.81 & 1.13 & 0.03 & 0.68 \\
\hline Intestinal section $^{1}$ & 1 & 390.24 & 390.24 & 31.89 & 0.37 & 0.014 \\
\hline Treatment $\times$ intestinal section & 2 & 18.43 & 9.22 & 0.75 & 0.02 & 0.746 \\
\hline Residual & 43 & 526.08 & 12.23 & & & \\
\hline Total & 49 & $1,029.0$ & & & & \\
\hline
\end{tabular}

\footnotetext{
${ }^{1}$ Ileum and colon.
} 

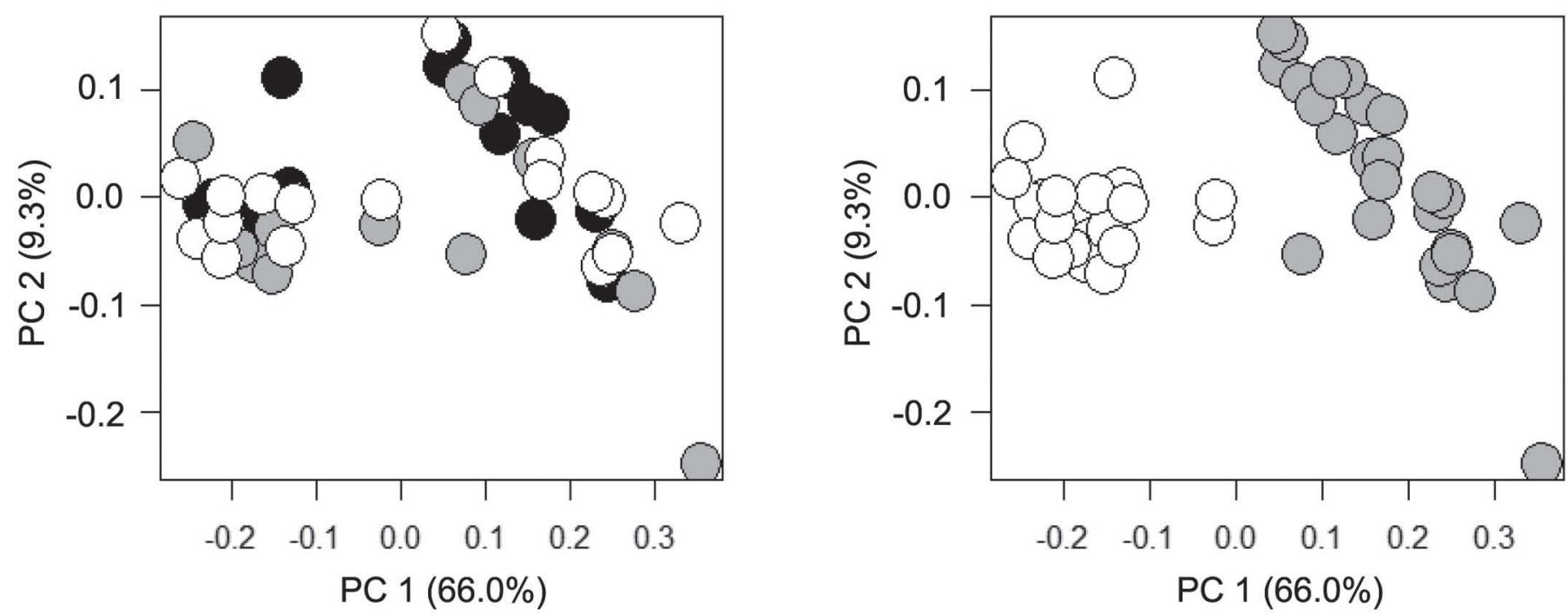

Figure 6. Intestinal mRNA samples ordered according to principal components (PC) analysis into control (gray diamonds), glucose (white circles), and 3-O-methyl glucose (black circles) (left panel); and ileum (white circles) and colon (gray circles) (right panel) of calves in experiment 2 .

contributes novel information on the range of milk intake within which functional responses to GLP-2 could be assessed.

Furthermore, there appears to be a major driver of GLP-2 secretion that is intrinsic to the individual calf. We detected a very large effect of basal secretion on maximal postfeeding plasma GLP-2 concentration, which was not related to either feeding rate or supplementation. This observation implies that either GLP-2 synthesis and release rates, clearance rates, or both vary from calf to calf. Calf variability in synthesis could be in turn due to total number of L cells, which can be thought of as the product of intestinal mass and L-cell density. On the other hand, clearance is proportional to the amount of dipeptidyl peptidase 4 (DPP4) secreted into circulation and renal clearance (Rowland and Brubaker, 2011). The bottom line is that possibly because of differences in such physiological traits, not all calves would benefit the same from a dietary intervention. To exploit this phenomenon, the variability in those underlying calf-specific features or some proxy of them needs to be estimated. The pre- and postprandial data presented here may aid power calculations to study between-calf variability in the above traits.
On the other hand, we could not detect an effect of glucose or 3-O-M-G supplementation on plasma GLP-2 concentration in either experiment 1 or 2 . We failed to approximate an effective dose range and, at a milk intake of $1.75 \%$ of $\mathrm{BW}$ as DM (i.e., experiment 1), the supply of glucose plus galactose from milk had probably already saturated the sweet receptor-GLP-2 signaling path. However, the data presented here indicate that the lack of effect was present even at low milk intakes $(0.43 \%$ of BW as DM), when the GLP-2 secretion response was far from being saturated. This would suggest that at such low intake levels, even if glucose could indeed trigger release of GLP-2 (Shirazi-Beechey et al., 2011) in calves, the total intake of glucose plus galactose $(\sim 85 \mathrm{~g} / \mathrm{d})$ from milk would be more than enough to saturate sweet receptor-mediated GLP-2 release; therefore, this mechanism would be active at total glucose plus galactose intake levels somewhere between 0 and $85 \mathrm{~g} / \mathrm{d}$. Response evaluation in this range deserves attention.

Taking into account that we used sheep data to set glucose doses, it is important to consider that sweettaste sensitivity and the concomitant signaling varies widely among species and even among strains within

Table 8 . Correlation between genes explaining $66 \%$ of variation in the glucagon-like peptide- 2 signaling pathway and principal component 1 (PC1) in experiment 2

\begin{tabular}{lcccccccc}
\hline PC & EGFR & AKT1 & NOS3 & NRG1 & GLP2R & IGF1R & SLC15A1 & PCNA \\
\hline PC1 & 0.94 & 0.91 & 0.91 & 0.9 & 0.8 & 0.78 & -0.51 & -0.44 \\
\hline
\end{tabular}


species (Pepino and Bourne, 2011). Thus, differences in sweet-taste sensitivity and specificity between sheep and calves might have accounted for the lack of GLP-2 response.

The distinctive profile of genes more abundantly expressed included GLP2R, EGFR, NOS3, NRG1, $I G F 1 R$, and $A K T 1$ in the colon, which suggests that GLP-2 signaling and the resulting trophic or restorative actions may be much better established in this organ compared with the ileum of calves. Similar transcription profiles were observed previously in bovines during various physiological stages (Connor et al., 2010). Specifically, this mRNA expression profile points to a greater sensitivity of the colon to circulating GLP-2 due to greater abundance of its receptor and downstream effectors. Indeed, in murine models, enhanced blood concentration of GLP-2 has been associated with increased concentration of circulating short-chain fatty acids (Tappenden et al., 1998) and colonic fiber fermentation (Cani et al., 2009), and both observations have resulted in improved epithelial function and intestinotrophic responses. These trophic responses are potentially mediated by IGF1 and EGF and their respective receptors, IGF1R and EGFR. As in the case of GLP2R, we noted that these 2 receptors were more abundantly present in colon than in ileum of calves. The effects of these receptors could be mediated downstream by the phosphoinositide 3 kinase/protein kinase B and ErbB pathways (Tappenden and McBurney, 1998; Rowland and Brubaker, 2011), and genes involved in these 2 signaling cascades were also distinctly expressed in the colon, but not the ileum, of calves used in this study. If the GLP-2 receptor and downstream effectors are actually more abundant in the calf colon, an opportunity exists to optimize the intestinal health and recovery responses to GLP-2 through, for instance, strategies that promote hindgut fermentation. In this sense, although conventional research has mostly focused on rumen development to accelerate weaning, research on the manipulation of GLP-2 secretion by dietary means, its effect on the development and function of the hindgut, and its restoration upon an illness episode could help decrease morbidity and mortality during the first few weeks of life.

\section{CONCLUSIONS}

Calves fed at $1.32,0.88$, and $0.44 \%$ of $\mathrm{BW}$ as $\mathrm{DM}$ presented plasma GLP-2 concentrations that were 87, 72 , and $49 \%$ of the concentration observed in calves fed at $1.75 \%$ of BW as DM. Given the important role of GLP-2 in intestinal homeostasis, these observations may be of practical importance with respect to new- born calves experiencing low milk intake due to illness or restricted-feeding programs. Provision of metabolizable or nonmetabolizable glucose did not affect GLP-2 secretion, intestinal growth, or gene expression in ileum or colon. Furthermore, this lack of response did not depend on the feeding rate of milk replacer. Dose-response curves for glucose intake below $85 \mathrm{~g} / \mathrm{d}$ and specific to the young calf need to be developed to identify the potential to trigger GLP-2 secretion and capitalize on its trophic or functional properties. Finally, genes related to the actions of GLP-2 were more highly expressed in the colon than in the ileum. Therefore, more work is needed to better understand the relationship between GLP-2, colon integrity, and health of newborn calves.

\section{REFERENCES}

Anderson, M. J. 2001. A new method for non-parametric multivariate analysis of variance. Austral Ecol. 26:32-46.

Brubaker, P. L., and Y. Anini. 2003. Direct and indirect mechanisms regulating secretion of glucagon-like peptide-1 and glucagon-like peptide-2. Can. J. Physiol. Pharmacol. 81:1005-1012.

Burrin, D. G., B. Stoll, and X. Guan. 2003. Glucagon-like peptide 2 function in domestic animals. Domest. Anim. Endocrinol. 24:103122.

Burrin, D. G., B. Stoll, R. Jiang, X. Chang, B. Hartmann, J. J. Holst, G. H. Greeley, and P. J. Reeds. 2000. Minimal enteral nutrient requirements for intestinal growth in neonatal piglets: How much is enough? Am. J. Clin. Nutr. 71:1603-1610.

Cani, P. D., S. Possemiers, T. Van de Wiele, Y. Guiot, A. Everard, O. Rottier, L. Geurts, D. Naslain, A. M. Neyrinck, D. M. Lambert, G. G. Muccioli, and N. M. Delzenne. 2009. Changes in gut microbiota control inflammation in obese mice through a mechanism involving GLP-2-driven improvement of gut permeability. Gut 58:1091-1103.

Connor, E. E., R. L. Baldwin VI, A. V. Capuco, C. M. Evock-Clover, S. E. Ellis, and K. S. Sciabica. 2010. Characterization of glucagonlike peptide 2 pathway member expression in bovine gastrointestinal tract. J. Dairy Sci. 93:5167-5178.

Connor, E. E., C. M. Evock-Clover, M. P. Walker, T. H. Elsasser, and S. Khal. 2015. Comparative physiology of glucagon-like peptide 2: Implications and applications for production and health of ruminants. J. Anim. Sci. 93:492-501.

Connor, E. E., S. Kahl, T. H. Elsasser, R. L. Baldwin, R. Fayer, M Santin-Duran, G. L. Sample, and C. M. Evock-Clover. 2013. Glucagon-like peptide 2 therapy reduces negative effects of diarrhea on calf gut. J. Dairy Sci. 96:1793-1802.

Davis, C. L., and J. K. Drackley. 1998. The Development, Nutrition, and Management of the Young Calf. 1st ed. Iowa State Univ. Press, Ames.

de Diego-Cabero, N., A. Mereu, D. Menoyo, J. J. Holst, and I. R. Ipharraguerre. 2015. Bile acid mediated effects on gut integrity and performance of early-weaned piglets. BMC Vet. Res. 11:111-119.

Drucker, D. J. 2005. Biologic actions and therapeutic potential of the proglucagon-derived peptides. Nat. Clin. Pract. Endocrinol. Metab. 1:22-31.

Drucker, D. J., P. Erlich, S. L. Asa, and P. L. Brubaker. 1996. Induction of intestinal epithelial proliferation by glucagon-like peptide 2 . Proc. Natl. Acad. Sci. USA 93:7911-7916.

Hartmann, B., A. H. Johnsen, C. Orskov, K. Adelhorst, L. Thim, and J. J. Holst. 2000. Structure, measurement, and secretion of human glucagon-like peptide-2. Peptides 21:73-80.

Ji, P., J. K. Drackley, M. J. Khan, and J. J. Loor. 2014. Inflammationand lipid metabolism-related gene network expression in visceral 
and subcutaneous adipose depots of Holstein cows. J. Dairy Sci. 97:3441-3448.

Johnson, D. E. 1998. Applied Multivariate Methods for Data Analysis. Duxbury Press, Pacific Grove, CA.

Littell, R. C., G. A. Milliken, W. W. Stroup, R. D. Wolfinger, and O. Schabenberger. 2006. SAS for Mixed Models. 2nd ed. SAS Institute Inc., Cary, NC.

Moriya, R., T. Shirakura, J. Ito, S. Mashiko, and T. Seo. 2009. Activation of sodium-glucose cotransporter 1 ameliorates hyperglycemia by mediating incretin secretion in mice. Am. J. Physiol. Endocrinol. Metab. 297:E1358-E1365.

Oksanen, J., F. G. Blanchet, R. Kindt, P. Legendre, P. R. Minchin, R. B. O'Hara, G. L. Simpson, P. Solymos, M. H. Stevens and H. Wagner. 2012. Vegan: Community ecology package. Accessed Apr. 28, 2106. http://CRAN.R-project.org/package=vegan .

Pepino, M. Y., and C. Bourne. 2011. Non-nutritive sweeteners, energy balance, and glucose homeostasis. Curr. Opin. Clin. Nutr. Metab. Care 14:391-395.

Pinheiro, J., D. Bates, S. DebRoy, D. Sarkar, and the R Core Team. 2015. Nlme: Linear and nonlinear mixed effects models. R package version 3.1-122. $\mathrm{R}$ The $\mathrm{R}$ Project for Statistical Computing, Vienna, Austria.

R Development Core Team. 2011. R: A language and environment for statistical computing. 3.1-104. R foundation for Statistical Computing, Vienna, Austria.

Ritz, C., and J. Streibig, ed. 2008. Non linear regression with R. 1st ed. Springer Science+Business Media, New York, NY.

Rowland, K. J., and P. L. Brubaker. 2011. The "cryptic" mechanism of action of glucagon-like peptide-2. Am. J. Physiol. Gastrointest. Liver Physiol. 301:G1-G8.

SAS Institute Inc. 2011. SAS/Stat 9.1 User's Guide. SAS Inst. Inc., Cary, NC.
Shirazi-Beechey, S. P., B. A. Hirayama, Y. Wang, D. Scott, M. W. Smith, and E. M. Wright. 1991. Ontogenic development of lamb intestinal sodium-glucose co-transporter is regulated by diet. J. Physiol. 437:699-708.

Shirazi-Beechey, S. P., A. W. Moran, D. J. Batchelor, K. Daly, and M. Al-Rammahi. 2011. Glucose sensing and signalling; regulation of intestinal glucose transport. Proc. Nutr. Soc. 70:185-193.

Tappenden, K. A., L. A. Drozdowski, A. B. Thomson, and M. I. McBurney. 1998. Short-chain fatty acid-supplemented total parenteral nutrition alters intestinal structure, glucose transporter 2 (GLUT2) mRNA and protein, and proglucagon mRNA abundance in normal rats. Am. J. Clin. Nutr. 68:118-125.

Tappenden, K. A., and M. I. McBurney. 1998. Systemic short-chain fatty acids rapidly alter gastrointestinal structure, function, and expression of early response genes. Dig. Dis. Sci. 43:1526-1536.

Taylor-Edwards, C. C., D. G. Burrin, J. J. Holst, K. R. McLeod, and D. L. Harmon. 2011. Glucagon-like peptide-2 (GLP-2) increases small intestinal blood flow and mucosal growth in ruminating calves. J. Dairy Sci. 94:888-898.

Taylor-Edwards, C. C. D. G. Burrin, J. C. Matthews, K. R. McLeod, J. J. Holst, and D. L. Harmon. 2010. Expression of mRNA for proglucagon and glucagon-like peptide-2 (GLP-2) receptor in the ruminant gastrointestinal tract and the influence of energy intake. Domest. Anim. Endocrinol. 39:181-193.

Vandesompele, J., K. De Preter, F. Pattyn, B. Poppe, N. Van Roy, A. De Paepe, and F. Speleman. 2002. Accurate normalization of real-time quantitative RT-PCR data by geometric averaging of multiple internal control genes. Genome Biol. 3:H0034.

Wøjdemann, M., A. Wettergren, B. Hartmann, and J. J. Holst. 1998. Glucagon-like peptide-2 inhibits centrally induced antral motility in pigs. Scand. J. Gastroenterol. 33:828-832. 